\title{
MODEL RAPID APPLICATION DEVELOPMENT (RAD) PADA APLIKASI MANAJEMEN SUMBER DAYA MANUSIA PT SPEKTA SOLUSI INDONESIA
}

\author{
Achyar Anshorie ${ }^{1)}$, Han Sulaiman ${ }^{2)}$ \\ ${ }^{1,2}$ Teknik dan Ilmu Komputer, Universitas Indraprasta PGRI \\ TB. Simatupang, Jl. Nangka Raya No.58 C, RT.5/RW.5, Tj. Bar., Kec. Jagakarsa, Kota Jakarta Selatan, \\ Daerah Khusus Ibukota Jakarta 12530 \\ email: achyar.anshorie@gmail.com ${ }^{1}$, mr.dehans@gmail.com ${ }^{2}$
}

\begin{abstract}
Article history Received June 15 , 2020

Revised July 19, 2019 Accepted July 28, 2019 Available online July 31, 2020
\end{abstract}

Keywords Rapid Application Development, Human Resources Management, HRIS,

$R A D$.

Riwayat

Diterima 15 Juni 2020 Revisi 19 Juni 2020 Disetujui 30 Juli 2020 Terbit 31 Juli 2020

Kata Kunci Rapid Application Development, Human Resources Management, HRIS,

RAD

\section{Abstract}

The progress of technology and information in the last few years has been developing very fast. One of them is marked by the application of the system to medium and large companies. At PT Spekta Solusi Indonesia The application of information systems in the management of human resources has not yet been realized, causing an impact on the service and distribution of information related to employees in it. Based on the existing problem the researcher wants to design an HRD information system to solve the problems faced by the company by using one of the system development methodologies namely Rapid Application Development $(R A D)$. The results of research in the form of HRD information system applications that can help improve the effectiveness and efficiency in data processing that can be used to support decision making. Application testing is done using black box testing which focuses on user input with the aim of checking the input form whether it is appropriate or not. Employee data management applications can be operated after going through black box testing and can run on web platforms such as Chrome, Mozilla Firefox or Safari.

Abstrak

Kemajuan teknologi dan informasi beberapa tahun terakhir ini berkembang sangat cepat. Salah satunya ditandai dengan penerapan sistem pada perusahan-perusahan menengah maupun besar. Pada PT. Spekta Solusi Indonesia penerapan sistem infomasi dalam pengelolaan sumber daya manusia belum terealisasi sehingga menyebabkan mengakibatkan dampak pada pelayanan dan distribusi informasi terkait pegawai di dalamnya. Berdasarkan masalah yang ada peneliti ingin merancang sebuah sistem informasi HRD untuk menyelesaikan permasalahan yang dihadapi perusahaan dengan menggunakan salah satu metodologi pengembangan sistem yaitu Rapid Application Development (RAD). Hasil penelitian berupa aplikasi sistem informasi HRD yang dapat membantu meningkatkan efektifitas dan efisiensi dalam pengolahan data yang dapat digunakan sebagai penunjang pengambilan keputusan. Pengujian aplikasi dilakukan menggunakan black box testing yang berfokus pada inputan pengguna dengan tujuan melakukan cek terhadap form input apakah sudah sesuai atau belum. Aplikasi manajemen data karyawan dapat dioperasikan setelah melalui pengujian black box testing dan dapat berjalan di platform web seperti Chrome, Mozilla Firefox atau Safari.

\section{PENDAHULUAN}

Kemajuan teknologi informasi akhirakhir ini berkembang sangat cepat. Salah satunya ditandai dengan penerapan sistem aplikasi pada perusahan-perusahan menengah maupun besar, Raymond McLeod,Jr. (2001). Hal ini juga berkaitan dengan kemudahan dan efektifitas dalam pengolahan data pegawai seperti penyimpanan data, update data, pencarian data sampai laporan data pegawai, sehingga 
penanganan pengolahan data pegawai lebih efisien dan efektif. Selain itu sistem juga sangat membantu permasalahan para pegawai dalam menyelesaikan pekerjaannya misalnya dalam hal gaji, tunjangantunjangan, upah lembur, cuti dan lain-lain.

Menurut Sutabri (2012) Sistem informasi adalah suatu sistem didalam suatu organisasi yang mempertemukan kebutuhan pengolahan transaksi harian yang mendukung fungsi operasi organisasi yang bersifat manajerial dengan kegiatan strategi dari suatu organisasi untuk dapat menyediakan kepada pihak luar tertentu dengan laporan-laporan yang diperlukan.

Manajemen Sumber Daya Manusia merupakan proses mendaya gunakan manusia sebagai tenaga kerja secara manusiawi agar potensi fisik dan psikis yang dimilikinya berfungsi maksimal bagi pencapaian tujuan organisasi atau perusahaan. (Nawawi, 2011)

Sebagaimana disebutkan sebagai sebuah proses, maka tentu saja memiliki tahapan dalam kegiatan pengelolaannya. Proses tersebut meliputi proses perencanaan, pengorganisasian, pengarahan, dan pengawasan kegiatan-kegiatan pengadaan, pengembangan, pemberian kompensasi, pengintegrasian, pemeliharaan, dan pelepasan Sumber Daya Manusia sehingga berbagai tujuan individu, organisasi, dan masyarakat dapat dicapai. (Rachmawati, I. K, 2008)

Saat ini pengolahan data karyawan pada PT. Spekta Solusi Indonesia penerapan sistem infomasi dalam pengelolaan sumber daya manusia belum terealisasi sehingga mengakibatkan dampak pada pelayanan dan distribusi informasi terkait pegawai di dalamnya. Hal ini mempersulit dalam pengelolaan seperti pencarian dan penyimpanan data karyawan, dari masalah yang ada maka penulis menyimpulkan bahwa kurangnya efektifnya pengolahan data pada bagian kepegawaian dimana prosedur yang dilakukan belum sepenuhnya terkomputerisasi. Oleh karena itu, penulis merasa perlu untuk membuat sebuah sistem aplikasi yang dapat mengatasi permasalahan untuk sistem pengolahan data karyawan. Sistem pengolahan data yang baru ini dapat dimanfaatkan secara efektif dan efisien, meskipun jumlah data yang relatif banyak dan keakuratan perhitungan dan laporan dapat dicapai semaksimal mungkin sehingga kesalahan dalam memasukan dan perhitungan data relatif tidak terjadi. Dengan sendirinya efisiensi waktu dan tenaga dalam pengerjaan dan penyelesaian suatu laporan akan jauh lebih baik.

\section{METODE PENELITIAN}

RAD merupakan gabungan dari bermacam-macam teknik terstruktur dengan teknik prototyping dan teknik pengembangan joint application untuk mempercepat pengembangan sistem/aplikasi. (Kendall, 2010).

Metode penelitian yang digunakan penulis adalah metode pengembangan aplikasi Rapid Application Development (RAD) dimana model proses pembangunan perangkat lunak yang tergolong dalam teknik incremental (bertingkat). RAD menekankan pada siklus pembangunan pendek, singkat, dan cepat Perhatikan gambar 1. 


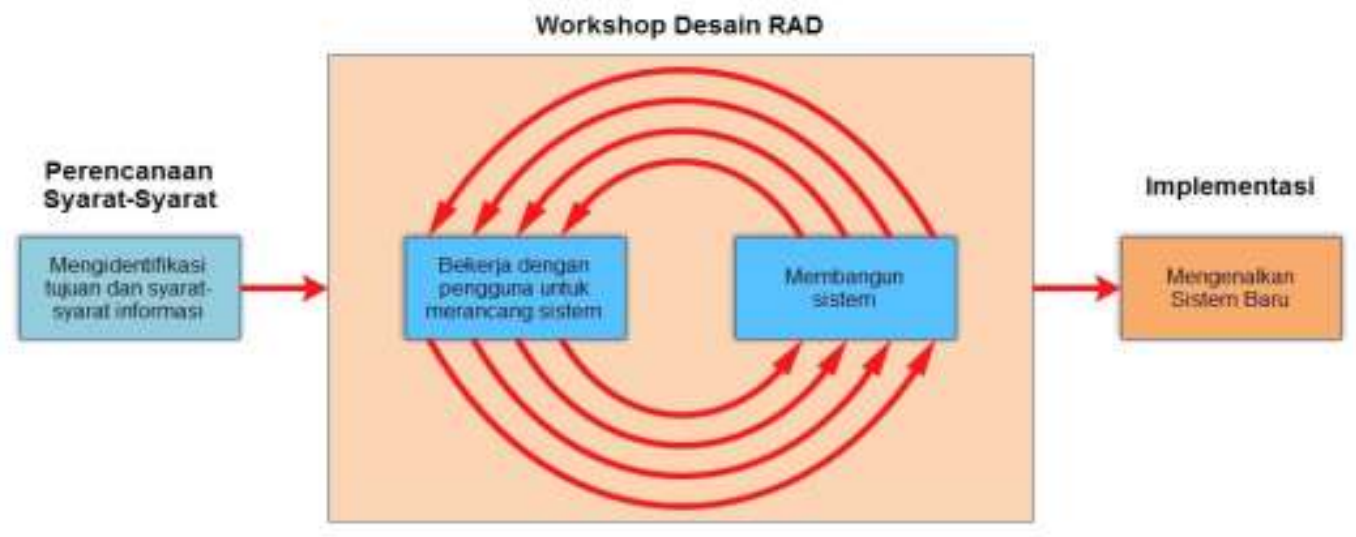

Gambar 1. Siklus RAD

Sumber: Kendall (2010)

\section{A. Pemodelan bisnis}

Pemodelan yang dilakukan untuk memodelkan fungsi bisnis untuk mengetahui informasi apa saja yang harus dibuat, siapa yang harus membuat informasi itu, bagaimana alur informasi itu, proses apa saja yang terkait informasi itu.

Tahapan ini penulis mengumpulkan bahan-bahan serta melakukan pengamatan terhadap kebutuhan aplikasi berbasis website. Informasi tersebut di analisis untuk mendapatkan spesifikasi system.

\section{B. Pemodelan data}

Memodelkan data apa saja yang dibutuhkan berdasarkan pemodelan bisnis dan mendefinisikan atributatributnya beserta relasinya dengan datadata yang lain. Tahapan ini penulis menggunakan ERD untuk pemodelan basis data sehingga dapat diketahui atribut apa saja yang diperlukan dan bagaimana relasi datanya.

\section{Pemodelan Proses}

Mengimplementasikan fungsi bisnis yang sudah didefinisikan terkait dengan pendefinisian data. Tahapan ini penulis menggunakan diagram alur data (DAD) sebagai identifikasi proses bisnis.
D. Pembuatan Aplikasi

Mengimplementasikan pemodelan proses dan data menjadi program. Model RAD sangat menganjurkan pemakaian komponen yang sudah ada jika dimungkinkan.

\section{E. Pengujian}

Seluruh unit yang dikembangkan dalam tahap implementasi diintegrasikan ke dalam sistem setelah pengujian yang dilakukan masing-masing unit. Setelah integrasi seluruh sistem diuji untuk mengecek setiap kegagalan maupun kesalahan.

\section{HASIL DAN PEMBAHASAN}

Seperti yang telah dijelaskan sebelumnya bahwa penelitian ini merupakan implementasi dari metode RAD, maka dari itu tahapan yang digunakan untuk Perancangan Aplikasi Sumber Daya Manusia Pada PT Spekta Solusi Indonesia ini sesuai dengan tahap-tahap berikut ini:

\section{A. Pemodelan Bisnis}

Berdasarkan Analisa yang di dapat ada emapat pengguna yang dapat mengakses system yaitu Karyawan, HRD Officer, Manajer Departemen, manajer HRD : 
a. Analisa Kebutuhan Karyawan

- Karyawan dapat melakukan absensi

- Karyawan dapat mengajukan cuti

b. Analisa Kebutuhan HRD Officer

- HRD Officer dapat membuat nama departemen

- HRD Officer dapat menginput data karyawan

- HRD Officer dapat menginput data keluar karyawan

- HRD Officer dapat menginput jabatan baru

- HRD Officer dapat mencetak surat keterangan

c. Analisa Kebutuhan Manajer Departemen

- Manajer Departemen melihat pengajuan cuti karyawan
- Manager Departemen dapat melakukan persetujuan cuti karyawan

d. Analisa Kebutuhan HRD Manajer

- HRD Manajer dapat melihat laporan data karyawan

- HRD Manajer dapat melihat laporan cuti karyawan

- HRD Manajer dapat melihat laporan absensi karyawan

- HRD manajer dapat melihat laporan keluar karyawan

B. Pemodelan Data

Entity Relationship Diagram (ERD) merupakan suatu model data yang dikembangkan berdasarkan objek. (Sutanta, Edhy, 2011)

Pemodelan data yang di tulis menggunakan Entity Relationship Diagram (ERD) sebagai berikut.

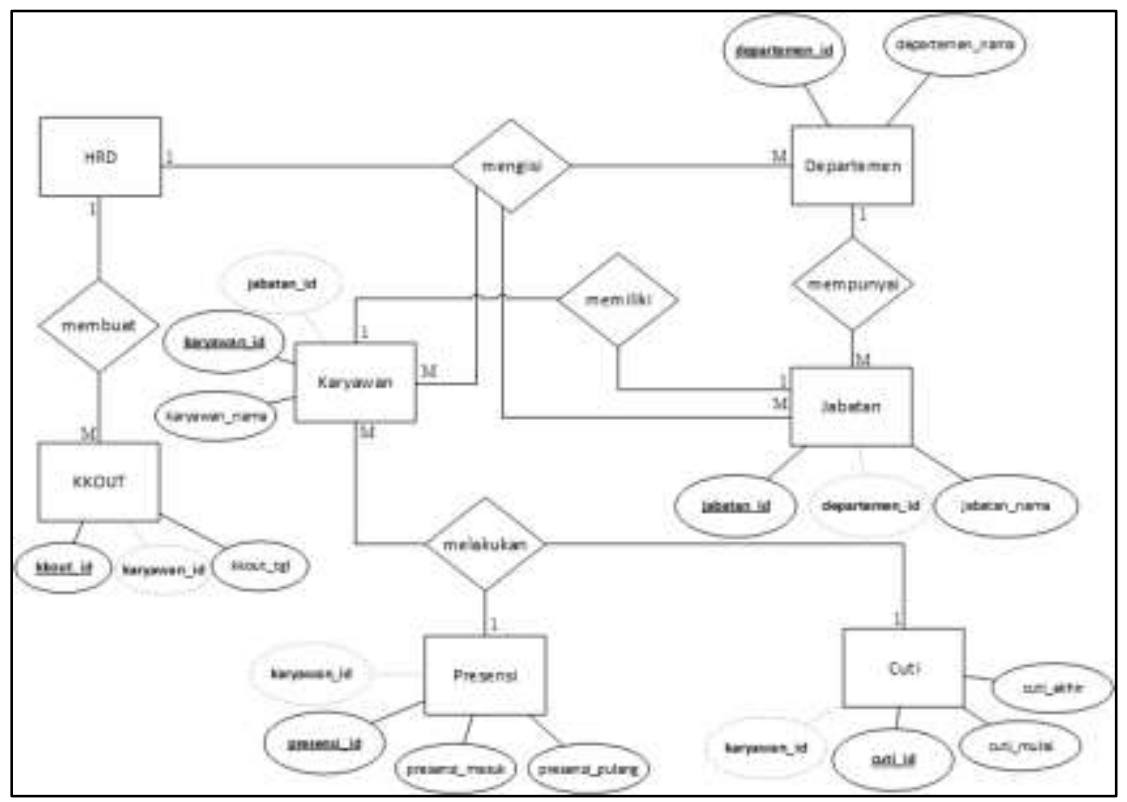

Gambar 2. Entity Relationship Diagram (ERD)

Pada gambar 2 diatas disajikan diagram keterhubungan relasi sebagai konsep usulan perancangan database dalam sistem usulan sistem pada PT Spekta Solusi Indonesia, dalam diagram keterhubungan relasi tersebut didapatkan 7 entity yang saling berelasi diantaranya : HRD, Departemen, KKOUT, Presensi, Karyawan, Jabatan, Presensi, dan Cuti.

\section{Pemodelan Bisnis}

Pemodelan bisnis disajikan dalam bentuk diagram nol sebagai sistem usulan sistem pada PT Spekta Solusi Indonesia, dalam diagram nol tersebut didapatkan 5 proses utama diantaranya : master, presensi, cuti, karyawan keluar (KKOUT), dan laporan. Proses proses tersebut dibutuhkan dalam 


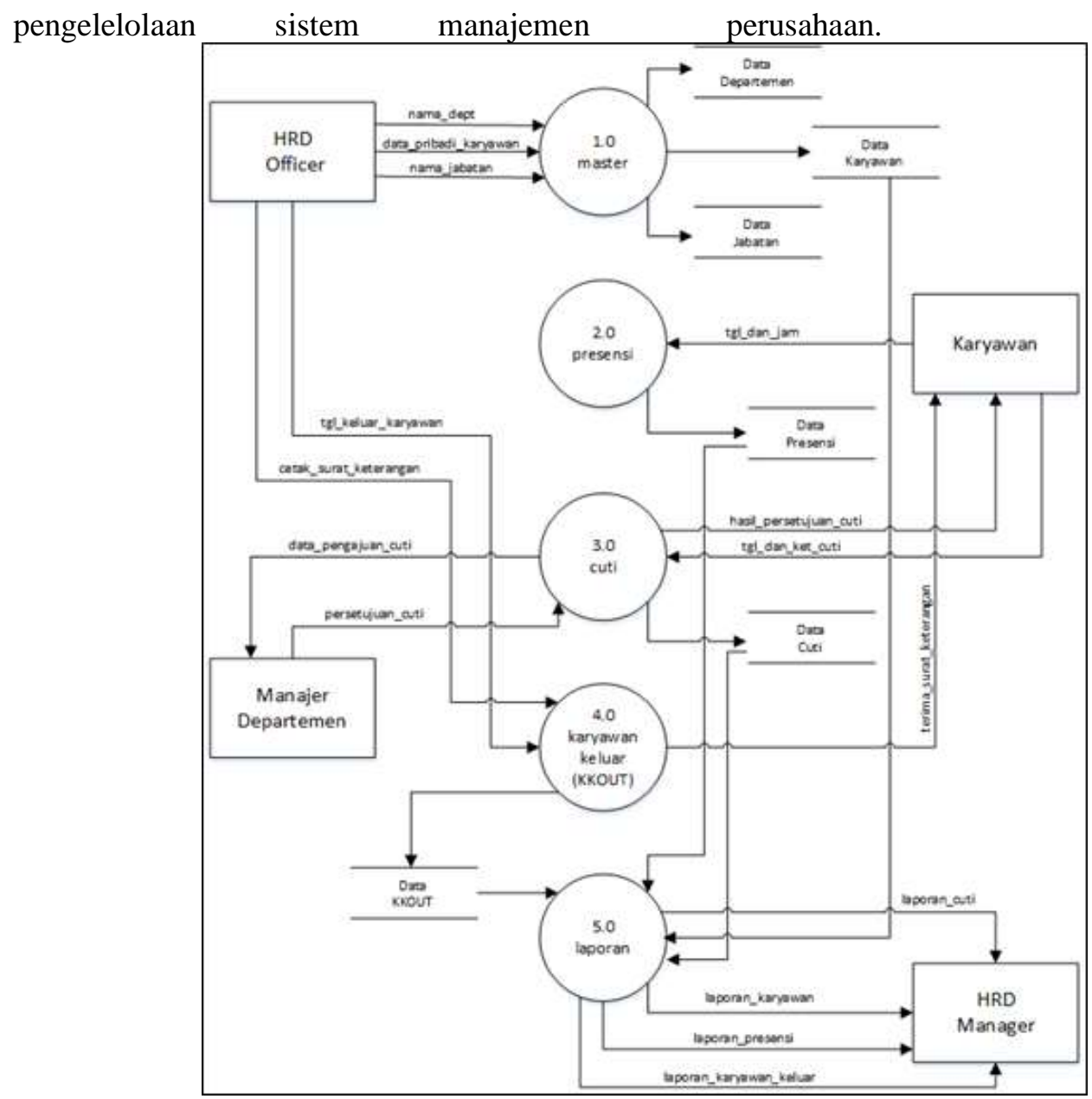

Gambar 3. Diagram Nol

\section{B. Pembuatan Aplikasi}

Tahap selanjutnya adalah tahap implementasi dimana penulis mengimplementasikan perencanaan sistem ke situasi nyata yaitu dengan pemilihan perangkat keras dan penyusunan perangkat lunak aplikasi (pengkodean/coding).

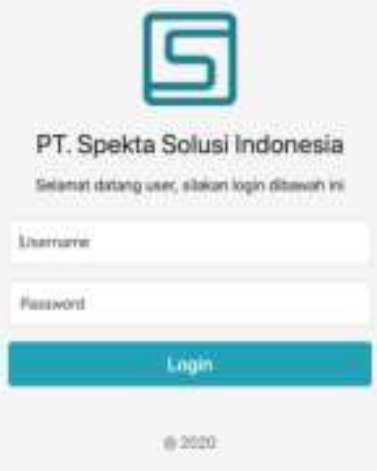

Gambar 4. Tampilan Form Login 
Pada Gambar 4 di atas terdapat pada awal program. Menu login digunakan sebagai kata kunci sebelum kita memasuki program utama. Agar tidak dapat orang mengakses program ini. Sehingga dalam form menu kerahasiaannya tetap terjaga dengan baik. Apabila pengguna dapat memasukan kata kunci dengan benar maka tombol menu utama akan aktif dan program siap digunakan.

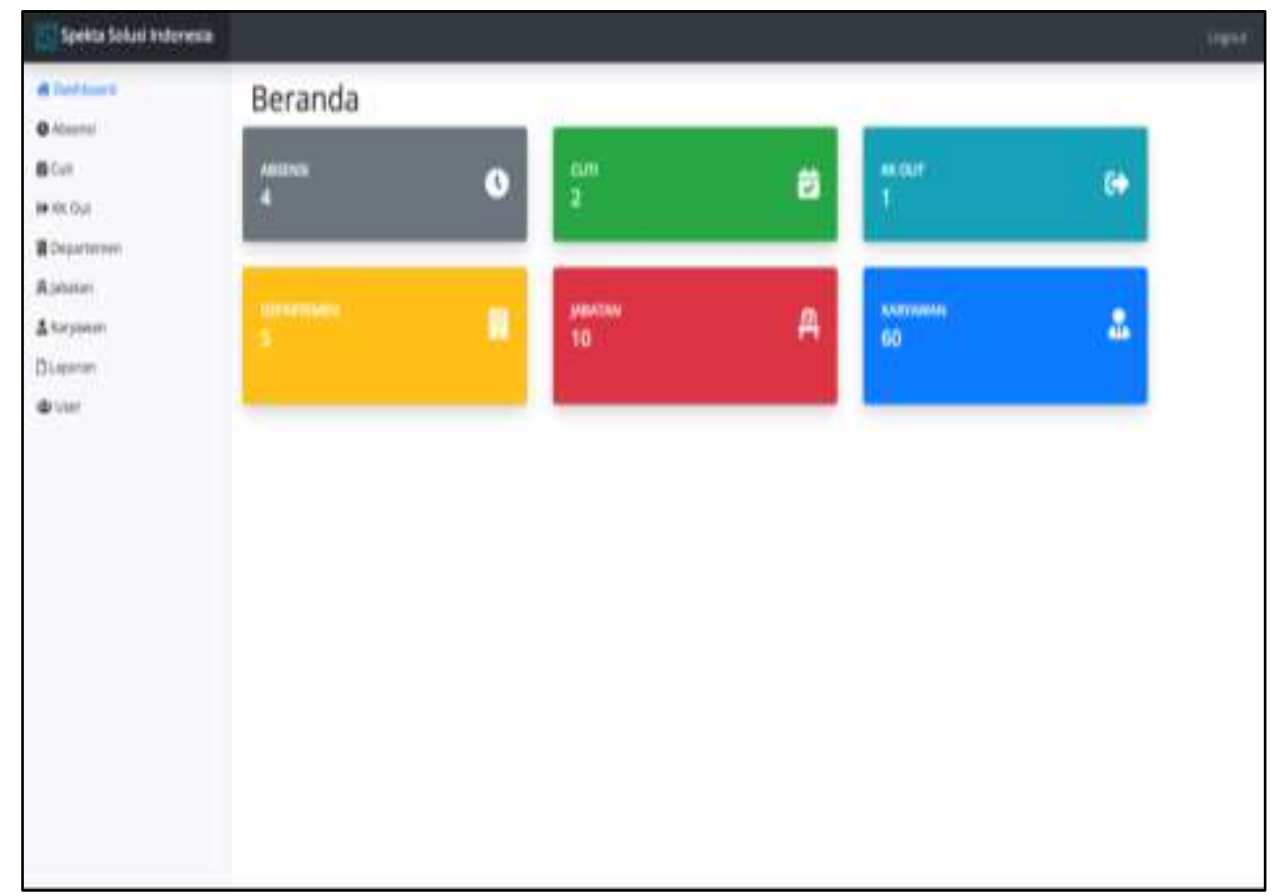

Gambar 5. Tampilan Dashboard

Pada Gambar 5 di atas menampilkan halaman seluruh menu yang ada pada aplikasi PT. Spekta Solusi Indonesia.

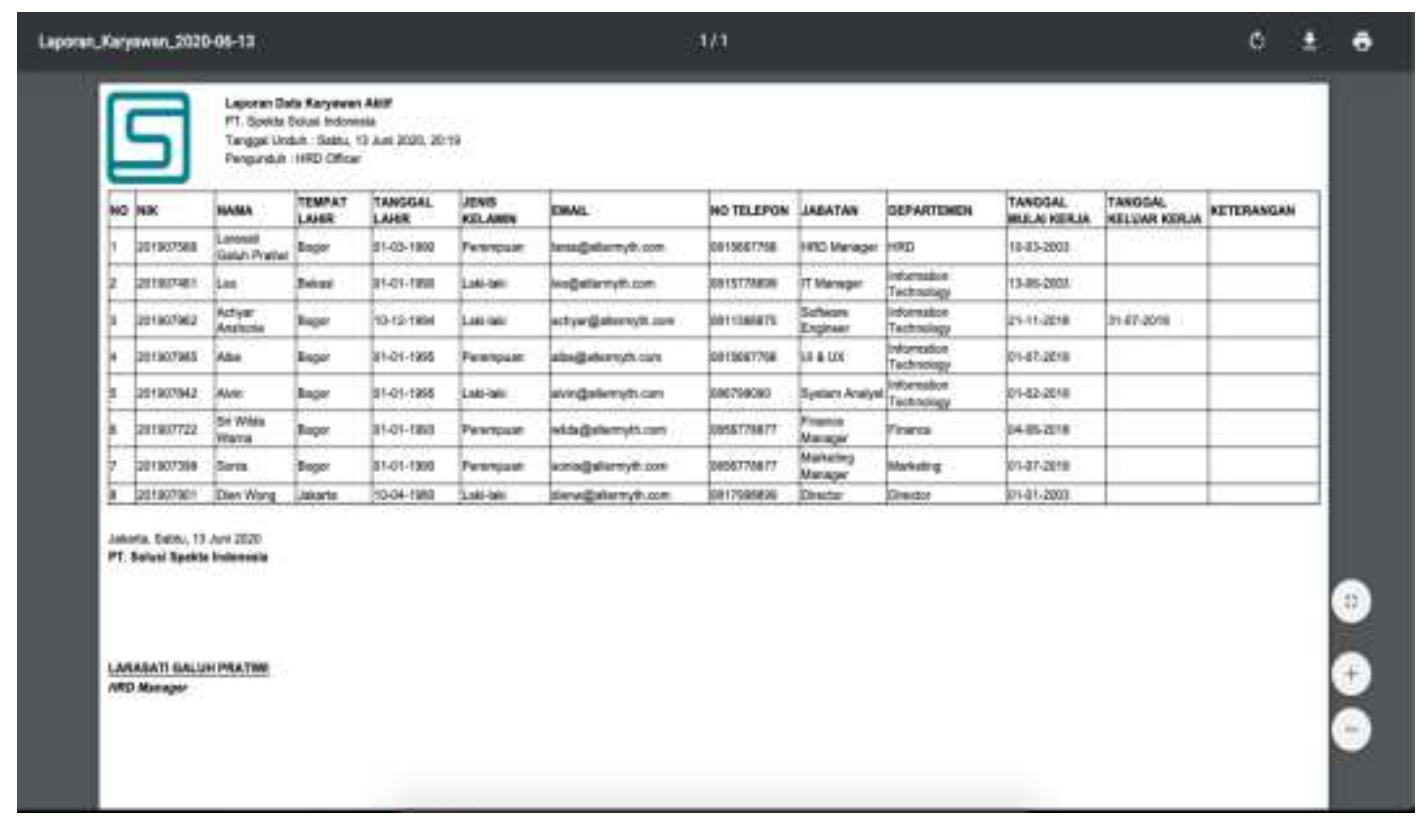

Gambar 6. Tampilan Laporan Data Karyawan 
Pada Gambar 6 di atas menampilkan keluaran laporan data karyawan yang bisa langsung di download maupun di cetak.

\section{Pengujian}

Setelah diterapkan kedalam tampilan tampilan asli dari aplikasi yang digunakan, maka tahap akhir yaitu pengujian, dimana pengujian ini dilakukan untuk mengetahui apakah aplikasi Manajemen Sumber Daya Manusia sudah sesuai dengan yang diinginkan, pengujian yang dilakukan adalah menggunakan pengujian dengan metode blackbox testing.

Black Box Testing (Pengujian Kotak Hitam) yaitu menguji perangkat lunak dari segi spesifikasi fungsional tanpa menguji desain dan kode program. Pengujian dimaksudkan untuk mengetahui apakah fungsifungsi, masukan, dan keluaran dari perangkat lunak sesuai dengan spesifikasi yang dibutuhkan. (Rosa, A.S., dan M. Shalahudin, 2014)

Tabel 1. Hasil Pengujian Black Box Testing Aplikasi Manajemen Sumber Daya Manusia

\begin{tabular}{|l|l|l|l|}
\hline \multicolumn{1}{|c|}{ Input/Even } & \multicolumn{1}{|c|}{ Proses } & \multicolumn{1}{c|}{ Output } & \multicolumn{1}{c|}{ Hasil Uji } \\
\hline Login & $\begin{array}{l}\text { Cek NIK dan } \\
\text { Password yang } \\
\text { terdaftar }\end{array}$ & $\begin{array}{l}\text { Muncul Halaman } \\
\text { Utama }\end{array}$ & Sesuai \\
\hline $\begin{array}{l}\text { Input Data } \\
\text { Karyawan }\end{array}$ & $\begin{array}{l}\text { Cek Nama, Jabatan, } \\
\text { Departemen, } \\
\text { Tanggal Lahir }\end{array}$ & $\begin{array}{l}\text { Akan menampilkan } \\
\text { NIK karyawan }\end{array}$ & Sesuai \\
\hline $\begin{array}{l}\text { Input Cuti } \\
\text { Karyawan }\end{array}$ & $\begin{array}{l}\text { Cek NIK dan } \\
\text { tanggal cuti }\end{array}$ & $\begin{array}{l}\text { Menampilkan } \\
\text { jumlah cuti yang } \\
\text { diambil }\end{array}$ & Sesuai \\
\hline $\begin{array}{l}\text { Input Presensi } \\
\text { Karyawan }\end{array}$ & $\begin{array}{l}\text { Cek NIK dan foto } \\
\text { karyawan }\end{array}$ & $\begin{array}{l}\text { Menampilkan Jam } \\
\text { masuk, telat atau } \\
\text { tidak }\end{array}$ & Sesuai \\
\hline $\begin{array}{l}\text { Menu Laporan Data } \\
\text { Karyawan }\end{array}$ & $\begin{array}{l}\text { Cek periode masuk } \\
\text { karyawan }\end{array}$ & $\begin{array}{l}\text { Menampilkan Data } \\
\text { Karyawan sesuai } \\
\text { periode }\end{array}$ & Sesuai \\
\hline $\begin{array}{l}\text { Menu Laporan Data } \\
\text { Cuti Karyawan }\end{array}$ & $\begin{array}{l}\text { Cek periode cuti } \\
\text { karyawan }\end{array}$ & $\begin{array}{l}\text { Menampilkan Data } \\
\text { Cuti Karyawan } \\
\text { sesuai periode }\end{array}$ & Sesuai \\
\hline $\begin{array}{l}\text { Menu Laporan } \\
\text { Presensi Karyawan }\end{array}$ & $\begin{array}{l}\text { Cek periode } \\
\text { presensi karyawan }\end{array}$ & $\begin{array}{l}\text { Menampilkan Data } \\
\text { Presensi sesuai } \\
\text { periode }\end{array}$ & Sesuai \\
\hline
\end{tabular}

Sumber: Hasil Penelitian (2019)

\section{KESIMPULAN}

Adapun beberapa kesimpulan yang dapat diambil dari pembuatan Aplikasi Manajemen Sumber Daya Manusia menggunakan metode RAD :

RAD selain membantu untuk mempercepat perancangan sistem juga sangat mudah di implementasikan karena langkah demi langkahnya sangat jelas, sehingga memudahkan pembuatan sistem, aplikasi dalam menentukan langkah awal hingga akhir pembuatan. Dengan adanya sistem manajemen sumber daya manusia ini dapat membantu kinerja petugas Human Resources Development (HRD) dapat meningkatkan 
kualitas dalam pengelolaan dan distribusi informasi sehingga lebih efektif dan efisien.

\section{REFERENSI}

Raymond McLeod,Jr. (2001). Sistem Informasi Manajemen Edisi 7 Jilid 2. Jakarta: Prenhallindo.

Sutabri. (2012). Analis Sistem Informasi. Yogyakarta: Andi.

Nawawi. (2011). Manajemen Sumber Daya Manusia: Untuk Bisnis Yang Kompetitif. Yogyakarta: Gajahmada University Press.
Rachmawati, I. K. (2008). Manajemen Sumber Daya Manusia. Yogyakarta: Andi.

J.E.K, Kendall, K.E. (2010). Analisis Perancangan Sistem. Jakarta: Indeks. $\rightarrow$

Sutanta, Edhy (2011). Basis Data Dalam Tinjauan Konseptual. Yogyakarta: Andi.

Rosa, A.S., dan M. Shalahudin. (2014). Rekayasa Perangkat Lunak. Bandung: Informatika 